\title{
Karbonmonoksit zehirlenmesi
}

\section{Carbonmonoxide poisoning}

\author{
Serkan Tursun ${ }^{1}$, Ayşegül Alpcan ${ }^{1}$, Cihat Şanlıํㄹ ${ }^{2}$ Mehmet Kabalc1 ${ }^{3}$ \\ ${ }^{1}$ Kırıkkale üniversitesi Tıp Fakültesi Çocuk Sağlığı Ve Hastalıkları AD, Kırıkkale \\ ${ }^{2}$ Kırıkkale üniversitesi Tıp Fakültesi Çocuk Kardiyolojisi BD, Kırıkkale \\ ${ }^{3}$ Kırıkkale Üniversitesi Tıp Fakültesi Kalp Damar Cerrahisi AD, Kırkkale
}

Geliş Tarihi:05.01.2017

Kabul Tarihi:05.12.2017

Doi:10.21601/ortadogutipdergisi.361864

\section{Öz}

Tatsız, kokusuz ve renksiz zehirli bir gaz olmasından dolayı "sessiz katil" olarak da tanımlanan karbonmonoksit, ölümcül zehirlenmelerin en sık sebeplerindendir. Tüm dünyada olduğu gibi ülkemizde de ciddi bir tehdittir. ABD'de her y1l karbonmonoksit zehirlenmesinden etkilenen 45 bin /500 milyon kişinin 4 bini ölürken, ülkemizde bu veriler net değildir. Spesifik bir antidot yoktur. En sık uygulanan tedavi yöntemi normobarik ve hiperbarik oksijen tedavisidir. Hiperbarik oksijen tedavisi nörolojik bulguları azaltılmasına da katkı sağlar.

Anahtar Kelimeler: Karbonmonoksit, zehirlenme

\begin{abstract}
Carbon monoxide, also known as silent killer because it is a tasteless, odorless and colorless toxic gas, is the most common cause of fatal poisonings. It is a serious threat to our country as it is in the whole world. In the United States, 4 out of 45,000 / 500 million people affected by carbon monoxide poisoning each year die, but this is not clear in our country. There is no specific antidote. The most common treatment method is normobaric and hyperbaric oxygen therapy. Hyperbaric oxygen therapy also contributes to the reduction of neurological findings.
\end{abstract}

Keywords: Carbon monoxide, poisoning

\section{Giriş}

Tatsiz, kokusuz ve renksiz zehirli bir gaz olmasindan dolayı sessiz katil olarak da tanımlanan karbonmonoksit, ölümcül zehirlenmelerin en sık sebebidir [1]. Gelişmiş ülkeler için önemli bir problem olsa da, ülkemiz gibi ekonomisi gelişmekte olan ülkeler için daha ciddi bir tehdittir. ABD'de her y1l karbonmonoksit zehirlenmesinden etkilenen 45 bin /500 milyon kişinin 4 bini ölürken [2] ülkemizde bu veriler net değildir.

ABD'de CO zehirlenmesinin en sk sebebi (\%57) egzoz gazlarının veya ortamdan uzaklaştırılamayan endüstriyel atık gazların teneffüsüne bağlıyken [3], ülkemizde karşılaş1lan en sık sebep ısınma ve sıcak su sağlanan sistemlerin uygun olmayan atık gaz uzaklaştırma ve baca sistemleri nedeniyle, özellikle rüzgârlı havalarda (lodos) artan ev kazaları şeklinde görülmektedir [4]. Şofben, kombi, katalitik ve odun-kömür gibi katı yakıt sobaları ve doğal gaz sobaları bu sistemlerin en sık karşılaşılan örnekleridir [5]. Gelişmiş ülkelere göre daha nadir olsa da motorlu araçların egzoz gazları ülkemiz için CO zehirlenme sebeplerindendir [6] . 


\section{Patogenez}

CO inhale edildiği zaman vücutta iki olay oluşur. Doku hipoksisi ve immünolojik ve inflamatuar etkiyle direkt hücre hasar1 [1]. CO'in hemoglobine afinitesi oksijenden yaklaşık 200-300 kat fazladır. Hemoglobine bağlanan CO ile karboksihemoglobin $(\mathrm{COHb})$ oluşur. Sonuçta dokulara sunulan oksijen azalır, oksihemoglobin dissosiyasyon eğrisi sola kayar ve rölatif anemi oluşur. Oksijen dağılımının bozulması sonucu özellikle oksijene en hassas bölgeler olan kalp ve beyin dokusunda hipoksi meydana gelir. Hipoksinin durumuna göre semptomlar ortaya çıkmaya başlar. CO gazının direk toksik etkisi sonucu hem içeren proteinler de (sitokromlar, myoglobulin, guanilsiklaz) etkilenir. Hücre nekrozu, rabdomyoliz, laktik asidoz oluşur [7].

\section{Klinik}

Akut CO zehirlenmesinde bulantı, kusma, halsizlik, baş ağrısı, baş dönmesi, kas krampları, karın ağrısı, dispne, göğüs ağrıs1, konsantrasyon güçlüğü, konfüzyon ve ataksi görülebilir [8]. Çocuklar, yaşlılar, kalp hastalığı olanlar, pulmoner hastalığı olanlar, hamileler diğer hastalar ile k1yaslandığında $\mathrm{CO}$ zehirlenmesi yönünde daha büyük risk altındadırlar [9]. Klinik ciddiyet inhale edilen CO miktarına, süresine, o andaki sağlık durumuna bağlıdır. Tüm sistemlerde toksik etki beklense de etki en yıkıcı etki santral sinir sistemi ve kardiyak sistem tutulumunda izlenmektedir [10]. Kliniğin ciddiyetine göre sıklıkla görülen sistemik bulgular Tablo 1'de gösterilmiştir [9].

\begin{tabular}{|l|l|l|l|}
\hline \multicolumn{3}{|l|}{ Tablo1. CO Zehirlenmesinde klinik } \\
\hline Ciddiyet & Nörolojik Bulgular & $\begin{array}{l}\text { Kardiyovasküler } \\
\text { sistem bulguları }\end{array}$ & Diğer bulgular \\
\hline Hafif & $\begin{array}{l}\text { Baş ağrısı } \\
\text { Baş dönmesi }\end{array}$ & $\begin{array}{l}\text { Bulantı } \\
\text { Kusma }\end{array}$ \\
\hline Orta & $\begin{array}{l}\text { Konfüzyon } \\
\text { Kuvvet kaybı } \\
\text { Ataksi } \\
\text { Bulanık görme }\end{array}$ & $\begin{array}{l}\text { Göğüs ağrısı } \\
\text { Taşikardi }\end{array}$ & $\begin{array}{l}\text { Takipne } \\
\text { Dispne }\end{array}$ \\
\hline Ciddi & $\begin{array}{l}\text { Oryantasyon } \\
\text { kayb1 } \\
\text { Nöbet } \\
\text { Koma }\end{array}$ & $\begin{array}{l}\text { Palpitasyon } \\
\text { Disritmi } \\
\text { Hipotansiyon } \\
\text { Miyokardiyaliskemi }\end{array}$ & $\begin{array}{l}\text { Pulmoner ödem } \\
\text { Renal yetmezlik }\end{array}$ \\
\hline
\end{tabular}

Baş ağrısı en erken tespit edilen ve en fazla beklenen bulgusudur. Diğer nörolojik bulgular baş dönmesi, 1şı̆̆a hassasiyet, güçsüzlük, konfüzyon, senkop, nöbet, koma olabilir. İleri evre intoksikasyonlarda beyin görüntülemesinde beyaz cevherde ve ganglionlarda nekroz tespit edilebilir [11]. Hastaların beşte birinde genellikle bir ay içinde görülen, hafıza ve zeka problemleri, kişilik değişiklikleri; dikkat ve konsantrasyon bozukluklarıla karakterize gecikmiş nöropsikiyatrik sendrom ortaya çıkabilse de bu durumun sevindirici yanı hastaların hemen hemen yarısı bir y1l içinde spontan olarak düzelmektedir [1]. Maalesef bu durumu tespit edecek klinik ve laboratuar belirteç yoktur. Ortaya çıkan bu durum hastaların \%60 kadarında ilk y1lda kaybolur [10]. \%3-10 arasında "gecikmiş nörolojik sekel" (GNS) gelişebilir [13]. Hipoksi sonucu indirekt olarak gelişen miyokardiyal iskemi ve kardiyak enzimlerde yüksekliği de izlenen miyokardiyal infarkt aritmi, egzersiz intolerans1, hipotansiyona neden olabilir. Disritmi aritmi kardiyak ölümün sebebi olabilir [9].

Karbonmonoksitin indüklediği hipoksi sonucu respiratuar alkaloz görülebilir. İleri dönemde laktik asidoza bağlı hastaların entübasyon ihtiyacı olabilir. Hastalarda solunum sıkıntıs1, pulmoner ödem, sağ kalp yetmezliği ve ARDS görülebilir $[11,12]$. Rabdomyolize bağlı akut tübüler nekroz veya CO'in direkt renal hücreler etkisi sonucu akut renal yetmezlik gelişebilir [7]. Nekroza bağlı ciltte kanamalar olabilir. Postmortem klasik bulgusu kiraz kırmızısı cilttir[12].

\section{Tanı}

Tanıda en önemli olan unsur hastalığın hikayesidir. Hastaların \%30 kadarında semptomlar nonspesifik olduğundan gözden kaçabilmektedir [9]. Gribal enfeksiyon, gastroenterit veya infantil kolik ile sıklıkla karışabilmektedir [1]. Taşikardi, takipne, baş ağrısı, bulantı, kusma, letarji gibi bulgularla gribal enfeksiyonu taklit edebilmektedir [11]. Dönem itibariyle hem soba mevsimi hem de gribal enfeksiyon mevsimi olması nedeniyle özellikle kış aylarına bu şikayetlerle gelen hastalar iyi sorgulanmalı, tanıda geç kalınmanın ölüm ile sonuçlanabileceği unutulmamalıdır. Bazen de kronik zehirlenmelerde çocuklarda okul başarısında düşüklük, görme bozukluğu, göğüs ağrısı, karın ağrısı gibi nonspesifik semptomlar olabilmektedir. Ayırıcı tanıda $\mathrm{CO}$ zehirlenmesi de düşünülmelidir $[1,12]$.

Hastalarda nabız oksimetre ile ölçülen oksijen satürasyonu eğer solunum sistemi etkilenmemiş ise genelde normal bulunur. Bu sebeple tanida pulse oksimetre bize yardımcı olmaz $[9,14]$. Arteriyel ve venöz kanda $\mathrm{COHb}$ düzeyi $\% 3$ 
üstünde olması tanıda faydalıdır fakat sigara içenlerde $\% 10$ civarına kadar yüksek çıkabileceği unutulmamalıdır. Eğer hasta acil servise geç getirildi ise veya acil servise gelmeden önce çok az da olsa oksijen tedavisi almış ise bu yükseklik tespit edilmeyebilir. Yani yüksekliği önemli iken düşük olması tanıy1 ekarte ettirmediği gibi tedaviye gereksinimin kalmadığını da göstermez. Çünkü rabdomiyoliz, nonkardiyojenik pulmoner ödem, mültiorgan yetmezliği, dissemine intravasküler koagülasyon defekti, akut tübüler nekroz, inkontinans, mutizm gibi gecikmiş nöropsikiyatrik komplikasyonlar kronik dönemde ortaya çıkabilmektedir. Bu sebeple klinik şüphe önemlidir [11,14]. Ayrıca $\mathrm{COHb}$ düzeyi hastalığın tedavisi esnasında da belirteç olarak kullanılabilir. Hastalarda serum laktat artışı ve metabolik asidoz varsa uzun süreli temas düşünmelidir [9,11]. Organ yetmezliği, doku hipoksisi açısından hemogram, karaciğer fonksiyon testleri, böbrek fonksiyon testleri, kas enzimleri, kardiyak enzimleri, idrar tetkiki istenmelidir. Klinik şüphe durumunda akciğer grafisi, beyin görüntüleme yöntemlerine başvurulmalıdır. İntoksikasyon için cilt ve mukozal tabakaların kiraz kırmızısı rengi patognomonik olmakla beraber ancak ölüm sonrası ortaya çıktığı için tanısal değeri yoktur [15].

\section{Tedavi}

Hasta zehirlenmeye neden olan CO kaynağından hızlıca uzaklaştırılmalı ve oksijen desteği sağlanmalıdır [16]. Hastaya 10-15 1/dk hızında \%100 oksijen geri solumasız maske ile başlanmalıdır. Şiddetli intoksikasyonlarda hastanın yoğun bakım ünitesine alınması ve entübe edilerek mekanik ventilasyon desteği başlanması akılda tutulmalıdır. Hastanın dikkatli olarak vital bulguları takip edilmeli, kardiyak parametreler monitorize edilmeli gelişen komplikasyonlar tedavi edilmelidir. Hastanın idrar çıkımı takip edilerek sıvı ihitiyacı replasmanla karşılanmalıdır. Hipotansiyon varsa hasta trandelenburg pozisyonuna getirilir, izotonik salin infüzyonu yapılır, gerekli ise vazopressörler ilaç başlanır, öncelikle dopamin tercih edilir. Dirençli hipotansiyon durumunda norepinefrin eklenir. Nörojenik nöbeti olan hastalara benzodiazepin verilmelidir. Yanıt alınamaz veya nöbet tekrarlarsa tedaviye fenobarbital gibi diğer antiepileptikler eklenir.

CO'in yarı ömrü oda havasında spontan solumayla 5 saat, $\% 100$ oksijen alırken 1,5 saat, 3 bar basınç hiperbarik oksijen (HBO) tedavisi altında 25 dakikadır [13]. Hastanın klinik durumuna göre yöntemlerden biri $\mathrm{COHb}$ duzeyleri $\% 5$ 'in altına düşene kadar uygulanmalıdır. Nörojenik hasar sonucu bilinç bulanıklığ1/kaybı izlenen hastalar, şiddetli asidozla takip edilen hastalar, miyokard tutulumu düşünülen hastalar için HBO tedavisi önerilmektedir [ 12].

Laktik asidoz dokular yoluyla oksijenin penetrasyonunu kolaylaştırdığından, $\mathrm{pH}$ değeri 7.15'in altında kalmadan düzeltilmemelidir [1].Ayrıca CO zehirlenmesinde kortikal hücre hasarının ve nöronal hasarın azaltılmasında hipotermiden yararlanılabileceğini bildiren çalışmalar bildirilmiştir [17].

\section{Maske ile oksijen tedavisi}

Hastaya klinik bulgular gerileyene kadar veya kardiyopulmoner komplikasyon yoksa $\mathrm{COHb}$ düzeyi \%5'in altına düşene kadar; kardiyopulmoner komplikasyon varsa $\mathrm{COHb}$ düzeyi \%2'nin altına düşene kadar verilmelidir. Genelde bu süre 4-6 saat kadar olmaktadır.

\section{Hiperbarik oksijen tedavisi}

Özellikle ilk 6 saatte uygulanabilen HBO tedavisi semptomların kısa sürede düzelterek mortaliteyi azaltır. HBO akut etkinin yanında süreç içinde yavaş yavaş ortaya çıkan nöropsikiyatrik semptomların önlenmesi konusunda da normobarik oksjen tedavisine göre daha başarılı bir yöntemdir. [18]. Eğer hastanın bilinç kaybı varsa veya hastaneye gelmeden önce bilinç kaybı olmuşsa HBO uygulanmalıdır [19]. Etkisinin başarısı 3 hafta sonra ortaya çıkan nöropsikiyatrik semptomlarda dahi olduğu gösterilmiştir $[9,20]$. Eğer mümkünse HBO ilk saat içinde başlanmalıdır. Eğer HBO tedavisi sonrası bilinç bulanıklığı devam ederse HBO 6-8 saat sonrasemptomlar gerileyene kadar tekrarlanmalıdır. Tablo2' de HBO tedavisi endikasyonları verilmiştir [21].

Tablo2. HBO tedavisi endikasyonları

- Görme bozukluğu

- Bilinç bozukluğu (geçici olsa bile)

- $\mathrm{COHb}$ düzeyi $\% 25$ 'in üstünde ise

• İnfant, çocuk, hamile kişide COHb düzeyi \% 15'in üstünde ise

- Hastada iskemik kalp hastalığı varsa COHb düzeyi \%20'nin üstünde ise

- EKG'de iskemi ve aritmi bulgusu varsa

- Herhangi bir klinik bulgu 3 haftadan uzun sürmüşse

- Klinik semptomlar normobarik oksijen tedavisi altında 4 saatten fazla uzadiysa 
Hasta hemodinamik olarak stabil değilse, kardiyopulmoner resusitasyon ihtiyacı varsa, hastada kronik bronşit veya amfizem varsa HBO tedavisinin uygulanması önerilmez [7,9,11]. Acil servise zehirlenmeler ile başvurular arasında CO zehirlenmesi oldukça önemli yer tutar [22]. Hastaların bazen nonspesifik semptom ile gelebileceği akıldan çıkarılmamalıdır. Ayrıntılı fizik öykü ve fizik muayene yaparken ayrıcı tanıda düşünülmelidir [23]. Hastalar ortaya çıkan bulgulara göre tedavi edilmeli hangi hastalar normobarik oksijen tedavisi hangi hastalara HBO tedavisi başlanacağ1na hasta bazında düşünerek karar verilmelidir.

\section{Maddi Destek ve Çıkar îlişkisi}

Çalışmayı maddi olarak destekleyen kişi/kuruluş yoktur ve yazarların çıkara dayalı bir ilişkisi yoktur.

\section{Kaynaklar}

1. Ernst A, Zibrak JD. Carbon monoxide poisoning. N Engl J Med 1998;339:1603-8.

2. Roughton FJW, Darling RC. Theeffect of carbonmonoxide on oxyhemoglobindissociationcurve. Am J Physiol 1944;141:17-31.

3. Wolf SJ, Lavonas EJ, Sloan EP, Jagoda AS; American College of Emergency Physicians. Clinical policy: Critical issues in the management of adult patients presenting to the emergency de- partment with acute carbon monoxide poisoning. Ann Emerg Med 2008;51:138-52

4. Uysalol M, Uysalol EP, Saraçoğlu GV, Kayaoğlu S. A Retro- spective Analysis of Pediatric Patients Admitted to the Pediatric Emergency Service for Carbon Monoxide Intoxication. Balkan Med J 2011;28:237-43

5. Besli GE, Ergüven M, Karadoğan M, Yılmaz Ö. Çocuklarda karbon monoksit zehirlenmesi. Akademik Acil Tıp Dergisi 2010;9:26-30.

6. Kocakaya M, Aydın B, Turla A, Özkanlı Ç. OMÜ Tıp fakültesi sağlık uygulama ve araştırma merkezine gelen karbon monoksit zehirlenmesi olgular1 - 2004. Solunum 2007;1:11-6.

7. Chavouzis N, Pneumatikos I. Carbonmonoxide inhalation poisoning. Pneumon 2014;27(1):16. 4. Roughton FJW, Darling RC. The effect of carbonmonoxide on oxyhemoglobin dissociation curve. Am J Physiol1944; 141:17-31. 5.Kao LW, Nanagas KA. Toxicityassociatedwithcarbonmonoxide. Clin Lab Med 2006;26:99-125.

8. Tomaszewski C. Carbon monoxide. In: Goldfrank LR, Somenbaum NE, Lewin NA Weisman RS, Howland MA, Hoffman A, editors. Goldfrank's Toxicologic Emergencies 5th ed. Norwalk, Connecticut: Appleton \& Lange 1994.p.199-210.

9. Gozubuyuk AA, Dag H, Kacar A, Karakurt Y, Arica V. Epidemiology, pathophysiology, clinical evaluationand treatment of carbon monoxide poisoningin child, infant, and fetüs. North Clin Istanb 2017 May 10;4:100-7
10. Prockop LD, Chichkova RI. Carbonmonoxide intoxication: an updatedreview. J Neurol Sci 2007;262:122-30.

11. Rucker J \& Fisher JA (2006). Carbonmonoxide poisoning. In Clinical Critical CareMedicine, ed. Albert RK, Slutsky AS, Ranieri M, Takala J \& Torres A, pp. 679-683. Mosby, Philadelphia, PA, USA.

12. Gorman DF, Clayton D, Gilligan JE, Webb RK: A longitudinal study of 100 consecutive admissions for carbonmonoxide poisoning to the Royal Adelaide Hospital. Anesth Intens Care 1992;20:311.

13. Choi IS. Delayed neurologic sequelae in carbon monoxide intoxication. Arch Neurol 1983;40:433-5.

14. HL Yılmaz. Karbon monoksit zehirlenmesi. cat.cu.edu.tr. Ulaşım tarihi Aralık 2017

15. Buckley NA, Isbister GK, Stokes B, Juurlink DN. Hyperbaric oxygen for carbon monoxide poisoning: a systematic review and critical analysis of the evidence. Toxicol Rev 2005;24:75-92.

16. Huzar TF, George T, Cross JM. Carbonmonoxide and cyanide toxicity: etiology, pathophysiology and treatment in inhalation injury. Expert Rev Respir Med 2013;7:159-70.

17. Penney DG. Chronic carbonmonoxide poisoning: a case series. In: Penney DG. editor. Carbon monoxide poisoning. Boca Raton, FL: CRC Press; 2008:551-67.

18. Weaver LK. Clinicalpractice: carbonmonoxidepoisoning. N Eng J Med 2009; 369:1217-25.

19. Weaver LK, Valentine KJ, Hopkins RO. Carbonmonoxidepoisoning: risk factors for cognitive sequelae and the role of hyperbaricoxygen. Am J Respir Crit Care Med 2007;176:491-7.

20. Hampson NB, Piantadosi CA, Thom SR, Weaver LK. Practicere commendations in the diagnosis, management, andprevention of carbonmonoxide poisoning. Am J Respir Crit Care Med 2012;186:1095-101.

21. Thom SR. Dehydrogenase conversion to oxidase and lipid peroxidation in brain after carbonmonoxide poisoning. J Appl Physiol 1992;73:1584-9.

22. Kao LW, Nanagas KA. Toxicity associated with carbonmonoxide. Clin Lab Med 2006; 26:99-125.

23. Hardy KR, Thom SR. Pathophysiology and treatment of carbonmonoxide poisoning. J Toxicol Clin Toxicol 1994;32:613-29.

Sorumlu Yazar: Ayşegül Alpcan, Çocuk Sağlığı ve Hastalıkları AD, Kırıkkale, Türkiye

E-mail: ozcalk@yahoo.com 